\title{
Aislamiento y caracterización de Streptomyces spp rizosféricos promotores del crecimiento vegetal
}

\author{
Isolation and characterization of Streptomyces spp \\ rizospheres promoters of vegetable growth
}

\author{
Condori-Pacsi, Sandro J. ${ }^{1 *}$, Fernández-Guzman, Patrick R. ${ }^{1}$, Valderrama-Valencia, María R. ${ }^{2}$
}

\section{RESUMEN}

Los Streptomyces son un grupo de actinobacterias considerados como habitantes del suelo escasamente estudiados en el campo de la biofertilización vegetal, y dentro de la economía peruana Allium sativum L., (ajo) es uno de los principales cultivos hortícolas de región de Arequipa. Por ello nos hemos propuesto en caracterizar a nivel morfológico, bioquímico y genético aislados de actinobacterias rizosféricas de una zona silvestres y examinar sus propiedades como promotores del crecimiento vegetal (PGPR) in vitro e in vivo sobre plántulas de Allium sativum $\mathrm{L}$. El análisis in vitro detectó a Streptomyces cirratus (ST3E) que fijo $0.63 \pm 0.01 \mathrm{mg} / \mathrm{L}$ nitrógeno atmosférico bajo la forma de amonio, también se detectó a Streptomyces sp (ST2A) como la mejor cepa que sintetizo $19.1 \pm 0.82 \mu \mathrm{g} / \mathrm{ml}$ de ácido indol acético y todas cepas presentaron un índice de solubilización de fosforo inorgánico entre 2.18 y 3.31 . El ensayo in vivo permitió detectar a Streptomyces cirratus (ST3E), este ha inducido al aumento del tamaño del vástago y aumento del peso seco, Streptomyces sp (ST2A), este aumento el tamaño de la raíz y las cepas Streptomyces sp (ST8A) y Streptomyces sp (ST8B), estos han inducido al aumento del diámetro del bulbo del ajo. Se propone a la cepa Streptomyces cirratus (ST3E) como candidato para profundizar estudios a nivel molecular como posible Streptomyces capaz de fijar el nitrógeno atmosférico, así mismo este estudio propone a Streptomyces cirratus (ST3E), Streptomyces $\mathrm{sp}$ (ST2A), Streptomyces $\mathrm{sp}$ (ST8A) y Streptomyces sp (ST8B) como buenos candidatos para ser incorporados en los bioformulados como agentes de biofertilización en el cultivo del ajo.

Palabras claves: actinobacterias, ajo, allium, biofertilizante nitrógeno, Streptomyces, PGPR.

\begin{abstract}
The Streptomyces are a group of actinobacteria considered as soil inhabitants sparsely studied in the field of plant biofertilization, and within the Peruvian economy Allium sativum L., (garlic) is one of the main horticultural crops in the Arequipa region. Therefore, we have proposed to characterize morphological, biochemical and genetic level, isolated rhizospheric actinobacteria of a wild area and examine their properties as plant growth promoting rhizobacteria (PGPR) in vitro and in vivo on seedlings of Allium sativum $L$. The in vitro analysis detected Streptomyces cirratus (ST3E) that fixed $0.63 \pm 0.01 \mathrm{mg} / \mathrm{L}$ atmospheric nitrogen in the form of ammonium, Streptomyces sp (ST2A) was also detected as the best strain that synthesized $19.1 \pm 0.82 \mu \mathrm{g} / \mathrm{ml}$ indole acetic indole acid, and all strains showed solubility indexes of inorganic phosphorus between 2.18 and 3.31. The in vivo test allowed to detect Streptomyces cirratus (ST3E), this has induced the increase of the size of the stem and increase of the dry weight and Streptomyces sp (ST2A), this increase the size of the root and the strains, Streptomyces sp (ST8A) and Streptomyces sp (ST8B), these have induced an increase in the diameter of the garlic bulb. Streptomyces cirratus (ST3E) is proposed as a candidate for deepend studies at molecular level as a possible fixer of atmospheric nitrogen. Strains of Streptomyces cirratus (ST3E), Streptomyces sp (ST2A), Streptomyces sp (ST8A) and Streptomyces sp (ST8B) are proposed as candidates for incorporation into bioformulates as biofertilization agents for the cultivation of garlic.
\end{abstract}

Key words: actinobacteria, garlic, allium, nitrogen biofertilizer, Streptomyces, PGPR.

\section{Introducción}

La agricultura intensiva hoy en día depende del uso constante de fertilizantes químicos que buscan mejorar el rendimiento de los productos hortícolas, sin embargo, el uso continuo de los productos fitosanitarios sintéticos está generando serios problemas ambientales, la agricultura

\footnotetext{
1 Instituto de Investigación Innovación y Desarrollo Biológico Ambiental I.I.D.B.A. S.A.C., Arequipa, Perú.

2 Escuela de Biología, Facultad de Ciencias Biológicas, Universidad Nacional de San Agustín, Arequipa, Perú.

* Autor de correspondencia: sandrojhonatan@correo.ugr.es; mvalderramav@unsa.edu.pe
}

Fecha de Recepción: 17 Marzo, 2019.

Fecha de Aceptación: 03 Mayo, 2019. 
intensiva y extensiva está ocasionando erosión y degradación de los suelos, aumentando de forma alarmante los problemas de fertilidad (Huang et al., 2011), poniendo en riesgo la salud humana. Los consorcios microbianos para la producción de biofertilizantes son una opción prometedora para reducir el uso de fertilizantes y pesticidas químicos, siendo actualmente un campo de investigación dentro de la agrobiotecnología. Los microorganismos rizosféricos, resultan ser beneficiosos para los sistemas suelo-planta debido a que estimulan la germinación de las semillas, promueven el enraizamiento, incrementan el suministro y disponibilidad de nutrientes, mejoran la estructura del suelo, y protegen a las plantas frente a estreses bióticos y abióticos (FrancoCorrea et al., 2010).

Las actinobacterias son un grupo ubicuo de microorganismos rizosféricos ampliamente distribuido en los ecosistemas naturales, pudiéndose encontrar en ambientes terrestres, acuáticos de agua dulce y marinos (Leiva et al., 2004). Como componentes de la microbiota del suelo, las actinobacterias participan en la degradación y mineralización de una gran cantidad de compuestos orgánicos (Ghanem et al., 2000), estos producen diversos compuestos bioactivos como las auxinas y giberelinas, por lo que son catalogadas como promotores del crecimiento vegetal (PGP) (Carro et al., 2016). Se han descrito actinobacterias con la capacidad de crecer en medios sin nitrógeno (Franco-Correa et al., 2010), y formar nódulos como Frankia sp (Yamanaka et al., 2016) y sintetizar antibióticos para el control de fitopatógenos (Xue et al., 2013 y Goudjal et al., 2014). Las actinobacterias han sido muy estudiadas en el campo farmacéutico desde 1940, mientras que en el campo agrícola hasta hace unos años se han descubierto sus propiedades benéficas como PGP (Minuto et al., 2006). Recientemente se ha descubierto que el grupo de los Streptomicetos, que por mucho tiempo se consideraron como habitantes del suelo de vida libre, tienen interacciones complejas con las plantas siendo beneficiosas como PGP (Seipke et al., 2011, Himaman et al., 2016, Sreevidya et al., 2016 y Yamanaka et al., 2016).

Por lo anterior, en este trabajo se planteó aislar Streptomyces nativas de la rizósferea de una planta silvestre, caracterizarlas a nivel morfológico y bioquímico, e identificarlas por análisis de su secuencia genética ARNr 16S, así como examinar sus propiedades como PGP in vitro e in vivo sobre plantulas de Allium sativum. Teniendo en cuenta que hay una falta de datos sobre el potencial benéfico de las actinobacterias PGP, este estudio proporciona información nueva sobre su capacidad de mejorar el crecimiento de una especie de valor comercial para la región de Arequipa.

\section{Materiales y Métodos}

\section{Aislamiento de las actinobacterias}

Las muestras se obtuvieron a partir de la rizósfera de Stevia sp. (silvestre), ubicada en una zona silvestre del Distrito de Chiguata

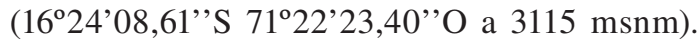
Un gramo de muestra se resuspendio en $9 \mathrm{ml}$ de agua peptonada $(0,1 \%$ de peptona) estéril, se diluyo hasta una dilución final de $10^{-4} \cdot 0,1 \mathrm{ml}$ fueron sembrados en agar avena (6\% de avena, $1,5 \%$ de agar), suplementado con $0,1 \%$ de nistatina como agente antifúngico y se incubaron a $28{ }^{\circ} \mathrm{C}$ durante 10 días (Xue et al., 2013). Las colonias de actinobacterias que presentaron un aspecto seco y pulverulento (Kampfer. 2012), fueron sub cultivadas en agar Czapek $\left(2 \mathrm{~g} / \mathrm{L} \mathrm{NaNO}_{3}, 0,5 \mathrm{~g} / \mathrm{L}\right.$ de $\mathrm{KCl}, 0,5 \mathrm{~g} / \mathrm{L}$ de $\mathrm{MgSO}_{4}, 0,01 \mathrm{~g} / \mathrm{L}$ de $\mathrm{FeSO}_{4}$, $1 \mathrm{~g} / \mathrm{L}$ de $\mathrm{K}_{2} \mathrm{HPO}_{4}, 30 \mathrm{~g} / \mathrm{L}$ de Sacarosa, $15 \mathrm{~g} / \mathrm{L}$ Agar, pH 7), para su purificación e incubadas durante 10 días a $28^{\circ} \mathrm{C}$. Las colonias purificadas fueron guardadas y conservadas en viales con glicerol $(25 \%)$ a $-20^{\circ} \mathrm{C}$.

\section{Caracterización morfológica y bioquímica}

Las cepas purificadas fueron sembradas en agar avena suplementada con nistatina al $1 \%$, e incubadas a $28^{\circ} \mathrm{C}$ por 10 días. Se examinaron las características del cultivo como: color del micelio aéreo, micelio de la base y producción de pigmentos difusibles. Las características morfológicas se observaron bajo microscopio óptico (Optika-100) siguiendo el manual de Bergey desarrollado por Kampfer (2012). Para la caracterización bioquímica se utilizaron diferentes azúcares como fuentes de carbono según el método de Gordon et al., (1974). Para la hidrólisis de la caseína, citrato, almidón y gelatina se siguió el método de Williams et al. (1983) y la hidrólisis de la urea según Gordon et al. (1974) 


\section{Extracción de ADN y secuenciación del gen ARN 16S}

El ADN genómico total se extrajo siguiendo el método SDS descrito por Yin et al. (2015). Para la amplificación por PCR del gen ARN 16S se usaron los cebadores universales $27 \mathrm{~F}$ ( $5 \mathrm{~g} /$ LAGAGTTTGATCCTGGCTCAG3 g/L), y 1492R (5 g/LACGGCTACCTTGTTACGACTT3 g/L). Los productos de la PCR fueron separados en gel de agarosa al $1 \%$ para su visualización y secuenciados comercialmente por MACROGEN (Corea del Sur). Las secuencias genéticas obtenidas, fueron procesadas con el programa MEGA 7,0. Las secuencias consensos fueron comparadas con las secuencias depositadas en el GenBank mediante la herramienta del Blast para nucleótidos del NCBI (https://blast.ncbi.nlm.nih.gov/Blast.cgi) y argadas a la base de datos del NCBI para obtener el número de acceso.

\section{Evaluación de las propiedades PGP in vitro}

\section{Crecimiento en medio libre de nitrógeno y cuantificación de amonio}

Para un cribado cualitativo, las cepas fueron sembradas en agar ashby $(20 \mathrm{~g} / \mathrm{L}$ de manitol, $0,2 \mathrm{~g} / \mathrm{L}$ de $\mathrm{CaCl}, 1 \mathrm{~g} / \mathrm{L}$ de $\mathrm{KH}_{2} \mathrm{PO}_{4}, 0,2 \mathrm{~g} / \mathrm{L}$ de $\mathrm{MgSO}_{4}$, $5 \mathrm{mg} / \mathrm{L}$ de $\mathrm{FeSO}_{4}, 0,2 \mathrm{~g} / \mathrm{L}$ de $\mathrm{NaCl}$ y $15 \mathrm{~g} / \mathrm{L}$ de Agar, $\mathrm{pH}$ 7.0) sin fuente de nitrógeno suplementado con $1 \mathrm{mg} / \mathrm{L}$ de molibdato de sodio y se incubaron a $28^{\circ} \mathrm{C}$ durante 15 días. Las colonias que lograron crecer después del tercer repique en el medio de cultivo fueron consideradas como capaces de crecer en un medio sin nitrógeno. La cuantificación de amonio se determinó por el método del fenol hipoclorito propuesto por Lara et al. (2007). Se cultivó $1 \mathrm{ml}$ de $10^{5}$ esporas $/ \mathrm{ml}$ en $9 \mathrm{ml}$ de medio líquido Ashby suplementado con $1 \mathrm{mg} / \mathrm{L}$ de molibdato de sodio, los cultivos se mantuvieron a $28^{\circ} \mathrm{C}$ sin agitación durante 10 días. Se centrifugaron $5 \mathrm{ml}$ del medio de cultivo a $5000 \mathrm{rpm}$ durante 10 minutos, al sobrenadante se añadió $0,5 \mathrm{ml}$ de solución alcohólica de fenol al 10\%, 0,5 ml de nitroprusiato de sodio al 0,5\% y $1 \mathrm{ml}$ de solución oxidante, la mezcla fue agitada y se dejó en reposo durante 1 hora. La medición de la absorbancia se tomó en un espectrofotómetro (FARLAB-120RS) a $632 \mathrm{~nm}$. La concentración de amonio se calculó a partir de una curva estándar con el cloruro de amonio.

\section{Producción de AIA}

Para cuantificar la producción de ácido indolacético (AIA) se cultivó $1 \mathrm{ml}$ de $10^{5}$ esporas $/ \mathrm{ml}$ en $9 \mathrm{ml}$ de caldo $\mathrm{B}\left(5 \mathrm{~g} / \mathrm{L}\right.$ de glucosa, $1 \mathrm{~g} / \mathrm{L}$ de $\mathrm{K}_{2} \mathrm{HPO}_{4}$, $0,2 \mathrm{~g} / \mathrm{L}$ de $\mathrm{MgSO}_{4}, 2 \mathrm{~g} / \mathrm{L}$ de $\mathrm{NH}_{4} \mathrm{NO}_{3}, 0,2 \mathrm{~g} / \mathrm{L}$ de $\mathrm{NaCl}, 5 \mathrm{mg} / \mathrm{L}$ de $\mathrm{FeSO}_{4}$, pH 7) suplementado con $20 \mathrm{~g} / \mathrm{L}$ de triptona, se mantuvo en agitación a 100 rpm durante 10 días a $28^{\circ} \mathrm{C}$. Fueron centrifugados $4 \mathrm{ml}$ del cultivo a $5000 \mathrm{rpm}$ durante 10 minutos, y según el protocolo de Szkop et al. (2011) al sobrenadante se le añadió $1 \mathrm{ml}$ de reactivo de Salkowski (Ácido sulfúrico 7.9M y Cloruro férrico $12 \mathrm{~g} / \mathrm{L})$. La producción de AIA se detectó por la presencia del color rosado o rojo. La medición de la absorbancia se tomó en un espectrofotómetro (FARLAB-120RS) a $530 \mathrm{~nm}$. La concentración de AIA se calculó a partir de una curva estándar con el ácido indol acético (Merck).

\section{Solubilización del fósforo}

Se cultivaron $0,1 \mathrm{ml}$ de $10^{5}$ conidios $/ \mathrm{ml}$ en el centro de placa con agar pycovskaya $[10 \mathrm{~g} / \mathrm{L}$ de glucosa, $2.5 \mathrm{~g} / \mathrm{L}$ de $\mathrm{Ca}_{3}\left(\mathrm{PO}_{4}\right)_{2}, 0,5 \mathrm{~g} / \mathrm{L}$ de $\left(\mathrm{NH}_{4}\right) 2 \mathrm{SO}_{4}, 0,2 \mathrm{~g} / \mathrm{L}$ de $\mathrm{NaCl}, 0,1 \mathrm{~g} / \mathrm{L}$ de $\mathrm{MgSO}_{4} \cdot 7 \mathrm{H}_{2} \mathrm{O}, 0,2 \mathrm{~g} / \mathrm{L}$ de $\mathrm{KCl}, 2 \mathrm{mg} / \mathrm{L}$ de $\mathrm{MnSO}_{4} \cdot \mathrm{H}_{2} \mathrm{O}, 2 \mathrm{mg} / \mathrm{L}$ de $\mathrm{FeSO}_{4} \cdot 7 \mathrm{H}_{2} \mathrm{O} 0,5$ de extracto de levadura y $15 \mathrm{~g} / \mathrm{L}$ de agar] y se incubaron a $30^{\circ} \mathrm{C}$ durante 10 días. El índice de solubilización (IS) se calculó siguiendo el método de Premono et al. (1996). Para determinar la capacidad de acidificar el medio se usó el método de Vázquez et al. (2000), para lo cual se sembraron las cepas por punción en agar SRSM [0,5 g/L de $\left(\mathrm{NH}_{4}\right) 2 \mathrm{SO} 4$, 0,2 g/L de $\mathrm{KCl}, 0,3 \mathrm{~g} / \mathrm{L}$ de $\mathrm{MgSO} 4,0,2 \mathrm{~g} / \mathrm{L}$ de $\mathrm{NaCl}, 5 \mathrm{~g} / \mathrm{L}$ de $\mathrm{Ca} 3(\mathrm{PO} 4) 2,4 \mathrm{mg} / \mathrm{L}$ de FeSO4, $10 \mathrm{~g} / \mathrm{L}$ de glucosa, $0,5 \mathrm{~g} / \mathrm{L}$ de extracto de levadura, $0,1 \mathrm{~g} / \mathrm{L}$ de purpura de bromocresol, $15 \mathrm{~g} / \mathrm{L}$ de agar, $\mathrm{pH}$ 7], y se incubaron a $28^{\circ} \mathrm{C}$ durante 5 días. $\mathrm{La}$ presencia de acidez se determinó por el cambio de color del medio de lila a amarillo.

\section{Evaluación de las propiedades PGP in vivo en Allium sativum}

Las cepas de actinobacterias aisladas fueron cultivadas en caldo Czapeck a una concentración de $10^{5}$ conidios/ml, se mantuvieron en agitación continua de $100 \mathrm{rpm}$ durante 10 días a $28^{\circ} \mathrm{C}$. Los dientes de ajo fueron esterilizados sumergiéndolos 
en hipoclorito de sodio al $1 \%$ durante 10 minutos, luego se enjuagaron con abundante agua estéril. Los dientes de ajo estériles fueron introducidos en la suspensión bacteriana durante una hora. Los dientes de ajo usados para el control fueron sumergidos en agua destilada estéril.

Los dientes de ajo tratados con las actinobacterias y con el tratamiento control fueron sembrados en macetas de plástico $(15 \mathrm{~cm}$ de alto x $10 \mathrm{~cm}$ diámetro) llenas de tierra estéril preparada (mezcla 1,1 tierra de campo de cultivo: arena) a una profundidad de $1 \mathrm{~cm}$. Las macetas de dispusieron en un bloque completamente aleatorizado con cinco réplicas por cepa, con condiciones de 14 horas luz y 10 horas de oscuridad, temperatura de entre $15-27^{\circ} \mathrm{C}$ dentro de un vivero. Todas las macetas se regaron diariamente con $10 \mathrm{ml}$ de agua destilada estéril. Después de 60 días las plantas se extrajeron cuidadosamente y se registraron los datos de longitud total, peso seco total y diámetro del bulbo. Los datos fueron analizados estadísticamente $(\mathrm{p}<0,05)$ con un análisis de varianza (ANOVA) y la prueba de especificidad de Tukey en el software SPSS 15,0.

\section{Resultados}

\section{Caracterización morfológica y bioquímica de las actinobacterias}

Se aislaron 11 colonias de actinobacterias a partir de la rizósfera silvestre de Stevia sp. Todas las colonias presentaron estructuras fibrilares tortuosas Gram positivas. En base a la estructura del micelio aéreo y la agrupación de las cadenas conidiales se agruparon en tres tipos: (1) cepas que presentaron cadenas recto-flexibles (ST2E, ST5B y ST8A), (2) cadenas espiraladas (ST3A), (3) cadenas recto-flexible con espirales (ST2A, ST2B, ST3E, ST3F, ST5A, ST5C, ST8B). El color de las esporas que presentaron fue gris y blanco. El color del micelio de la base presentó coloraciones: marrón, crema, verde y anaranjado. Los pigmentos difusibles en su mayoría fueron de color marrón, con excepción de ST2A y ST5B que no presentaron pigmentos.

En la Tabla 1 se puede observar que los azúcares glucosa, galactosa, sucrosa y manitol, fueron utilizados como fuetes de carbono por todas las actinobacterias aisladas, la lactosa fue utilizada sólo por las cepas ST2E, ST8A y ST8B; la arabinosa por las cepas ST3A, ST3E, ST5B, ST5C, ST8A y ST8B; y la xilulosa por las cepas ST5C, ST8A y ST8B. Todas las actinobacterias aisladas hidrolizaron al citrato, almidón y la caseína, la urea y la gelatina fue hidrolizada solo por algunas cepa como está indicado en la Tabla 1.

\section{Características PGP de las actinobacterias}

El cultivo de las actinobacterias en el medio en agar ashby libre de nitrógeno, permitió identificar ocho colonias, que presentaron la capacidad de crecer en un medio libre de nitrógeno después del tercer repique (Tabla 2). Dichas cepas fueron cultivadas en un medio líquido libre de nitrógeno el cual permitió detectar y cuantificar la presencia de amonio. La cepa ST3E presentó la más alta concentración de amonio en el medio de cultivo $(0,63 \pm 0,04 \mathrm{mg} / \mathrm{ml})$, seguido de las cepas ST2A y ST5C con una concentración de $0,17 \pm 0,01 \mathrm{mg} / \mathrm{ml}$ y $0,11 \pm 0,01 \mathrm{mg} / \mathrm{ml}$ de amonio, respectivamente.

El cultivo de las actinobacterias aisladas en el agar pycovskaya, permitió identificar que todas las cepas presentaron la capacidad de solubilizar el fósforo por la formación de un halo incoloro alrededor de las colonias. La Tabla 2 presenta los mayores índices de solubilización (IS), de 3,31 y 3,10 alcanzados por las cepas ST3A y ST5A respectivamente. Las demás colonias presentaron IS por encima de 2.18. El cultivo de las cepas en el agar SARM permitió identificar que las cepas presentan la capacidad de acidificar el medio de cultivo.

El cultivo de todas las actinobacterias en caldo B permitió identificar nueve cepas que presentan la capacidad de sintetizar la hormona ácido indol acético (AIA). La cuantificación de este producto permitió identificar que la cepa ST2A presentó la más alta concentración de AIA $(19,1 \pm 0,82 \mu \mathrm{g} /$ $\mathrm{ml}$ ) a los 10 días de cultivo, El resto de las cepas presentaron concentraciones de AIA por encima de $\operatorname{los} 4,3 \mu \mathrm{g} / \mathrm{ml}$.

\section{Evaluación de las PGP in vivo de las actinobacterias aisladas en Allium sativum}

Los efectos del crecimiento del vástago y la raíz de Allium sativum (ajo) por inoculación con las actinobacterias aisladas se observa en la sección A de la Figura 1, donde el tratamiento con la cepa ST3E promovió un incremento significativo del 
Tabla 1. Características de morfológicas y bioquímicas de las cepas de actinobacterias rizosféricas aisladas.

\begin{tabular}{|c|c|c|c|c|c|c|c|c|c|c|c|}
\hline \multirow{2}{*}{ Características } & \multicolumn{11}{|c|}{ Cepas aisladas } \\
\hline & ST2A & ST2B & ST2E & ST3A & ST3E & ST3F & ST5A & ST5B & ST5C & ST8A & ST8B \\
\hline \multicolumn{12}{|c|}{ Morfología de las cadenas conidiales } \\
\hline Recto-flexible & - & - & + & - & - & - & - & + & - & + & - \\
\hline Espirales & - & - & - & + & - & - & - & - & - & - & _- \\
\hline Recto-flexibles con espiral & + & + & - & - & + & + & + & - & + & - & + \\
\hline \multicolumn{12}{|l|}{ Color de la masa de esporas } \\
\hline Gris & - & + & + & + & - & - & - & - & - & + & + \\
\hline Blanco & + & - & - & - & + & + & + & + & + & - & - \\
\hline \multicolumn{12}{|l|}{ Color de micelio de la base } \\
\hline Marrón & - & + & + & - & - & + & + & - & - & - & - \\
\hline Crema & + & - & - & + & + & - & + & + & - & - & - \\
\hline Verde & - & - & - & - & - & - & - & - & - & + & + \\
\hline Anaranjado & - & - & - & - & - & - & - & - & + & - & - \\
\hline Pigmentos difusibles & - & Marrón & Marrón & Gris & Marrón & Marrón & Marrón & - & Amarillo & Verde & Verde \\
\hline \multicolumn{12}{|l|}{ Fuentes de carbono } \\
\hline Glucosa & + & + & + & + & + & + & + & + & + & + & + \\
\hline Galactosa & + & + & + & + & + & + & + & + & + & + & + \\
\hline Sucrosa & + & + & + & + & + & + & + & + & + & + & + \\
\hline Manitol & + & + & + & + & + & + & + & + & + & + & + \\
\hline Lactosa & - & - & + & - & - & - & - & - & - & + & + \\
\hline Arabinosa & + & + & - & + & + & - & - & + & + & + & + \\
\hline Xilulosa & - & - & - & - & - & - & - & - & + & + & + \\
\hline \multicolumn{12}{|l|}{ Hidrólisis de } \\
\hline Urea & - & - & + & + & + & - & - & + & + & - & - \\
\hline Citrato & + & + & + & + & + & + & + & + & + & + & + \\
\hline Caseina & + & + & + & + & + & + & + & + & + & + & + \\
\hline Gelatina & + & + & + & - & + & - & - & + & + & + & + \\
\hline Almidón & + & + & + & + & + & + & + & + & + & + & + \\
\hline
\end{tabular}

$+=$ reacción positiva/crecimiento positivo, $-=$ reacción negativa/crecimiento negativo.

Tabla 2. Caracterización de las actinobacterias rizosféricas aisladas por sus caracteres como promotores del crecimiento vegetal en condiciones in vitro.

\begin{tabular}{lccccc}
\hline \multirow{2}{*}{ Aislados } & \multicolumn{2}{c}{ Nitrógeno } & \multicolumn{2}{c}{ Fósforo } & \multirow{2}{*}{ AIA } \\
\cline { 2 - 5 } & MSN & $\mathrm{NH}_{4}{ }^{+}(\mathrm{mg} / \mathrm{L})$ & $\mathrm{IS}$ & SARM & $(\mu \mathrm{g} / \mathrm{ml})$ \\
\hline ST-2A & + & $0,17 \pm 0,01$ & 2,53 & + & $19,1 \pm 0,82$ \\
ST-2B & + & $0,05 \pm 0,01$ & 2,64 & + & $8,8 \pm 0,16$ \\
ST-2E & + & $0,03 \pm 0,01$ & 2,90 & + & $0,0 \pm 0$ \\
ST-3A & - & $0,0 \pm 0$ & 3,31 & + & $4,3 \pm 0,22$ \\
ST-3E & + & $0,63 \pm 0,04$ & 2,61 & + & $0,0 \pm 0$ \\
ST-3F & - & $0,0 \pm 0$ & 2,60 & + & $9,2 \pm 0,3$ \\
ST-5A & - & $0,0 \pm 0$ & 3,10 & + & $4,4 \pm 0,16$ \\
ST-5B & + & $0,08 \pm 0,01$ & 2,18 & + & $5,4 \pm 0,2$ \\
ST-5C & + & $0,11 \pm 0,01$ & 2,65 & + & $4,4 \pm 0,12$ \\
ST-8A & + & $0,07 \pm 0,01$ & 2,52 & + & $6,4 \pm 0,17$ \\
ST-8B & + & $0,03 \pm 0,01$ & 2,94 & + & $6,2 \pm 0,23$ \\
\hline
\end{tabular}

$\mathrm{NH}_{4}^{+}$:Amoonio, IS: Índice de solubilización, MSN: medio sin nitrógeno. SARM: medio de cultivo sin fósforo, AIA: Ácido indol acético.
$43,5 \%$ en el tamaño del vástago con respecto al control. La cepa ST2A promovió un incremento significativo del 89,6\% en el tamaño de la raíz, seguido de ST3F y ST2B que permitieron un incremento significativo de $61 \%$ y $60,7 \%$ respecto al control.

El bulbo del ajo también presentó un incremento significativo en el diámetro, al ser inoculados con las actinobacterias. En la sección B de la Figura 1 se observa que todas las cepas permitieron el aumento del diámetro del bulbo del ajo, siendo las cepas ST8B, ST8A, ST3A, ST2E, ST3F y ST2B que promovieron un incremento del $46,4 \%, 46,4 \%$, $45,3 \%, 44,5 \%, 41,9 \%$ y $37,0 \%$ respectivamente, respecto al control.

El peso seco total de las plántulas de ajo también aumentó significativamente respecto al 

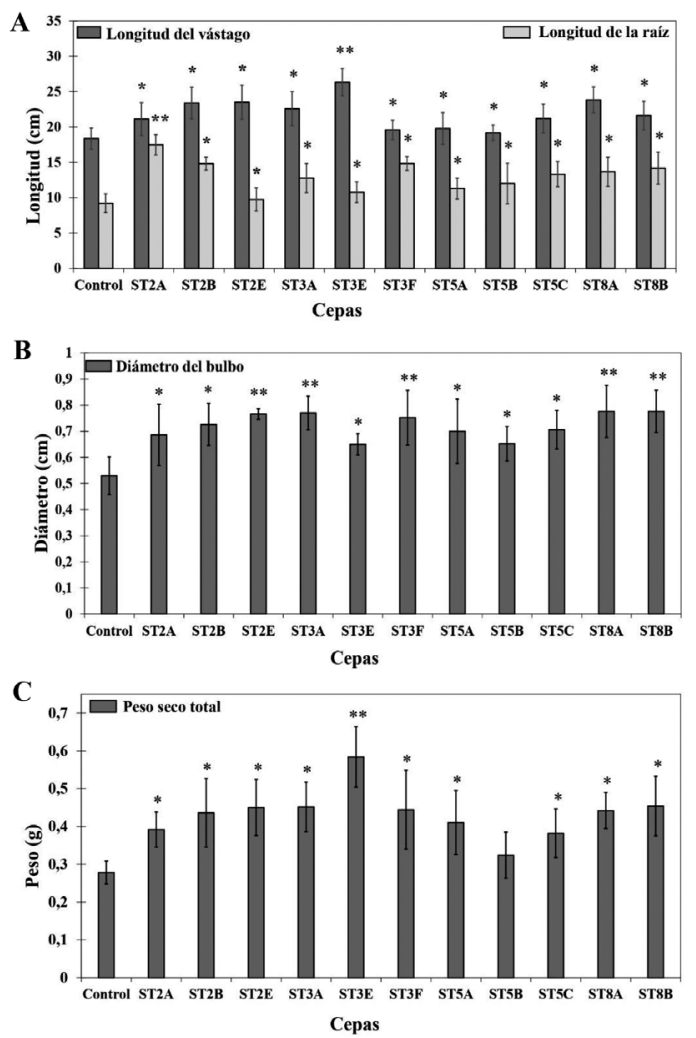

Figura 1. Efectos de PGP de las actinobacterias aisladas en Allium sativum (A) Longitud del vástago y longitud de la raíz de las plantas (cm). (B) Diámetro del bulbo del ajo (cm). (C) Peso seco de las plantas de ajo en gramos (gr). La evaluación se realizó a los 60 días del cultivo. Las barras representan el promedio de 5 repeticiones. Los asteriscos en las barras indican la existencia de diferencias significativas (tukey, $\mathrm{p}<0.05$ ), respecto al control las barras con doble asterisco indican la existencia de diferencias altamente significativa (tukey, $\mathrm{p}<0.01$ ) respecto al control y los demás tratamientos.

control. En la sección C de la Figura 1 se observa que la cepa ST3E indujo un incremento de 101,1\% con respecto al control, siendo la cepa que mejor indujo el incremento en el peso seco. Las cepas ST8B, ST3A, ST2E indujeron el incremento del peso seco en $63,3 \%, 62,6 \%$ y $61,9 \%$ respectivamente.

\section{Identificación de las actinobacterias aisladas por secuenciación del gen ARNr 16S}

Todas las actinobacterias rizosféricas fueron procesadas para la amplificación por PCR del gen ARNr 16S. La utilización de cebadores universales permitió obtener una banda de $1,5 \mathrm{~Kb}$ como producto génico (Figura 2). Las secuencias de los productos génicos fueron analizados por comparación con

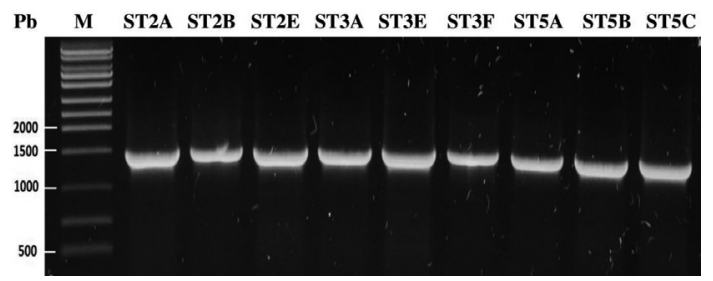

Figura 2. Electroforesis en gel de agarosa de los productos de la PCR para la detección de los aislados de las actinobacterias. Los productos de PCR presentaron un peso de $1.5 \mathrm{~Kb}$. $(\mathrm{Pb})$ Pares de bases. (M) escalera del marcador de peso molecular.

las secuencias depositadas en el GenBank a travez de Nucleotide BLAST (https://blast.ncbi.nlm.nih. gov/Blast.cgi). Las cepas ST3A, ST3E y ST5C presentaron una similitud del $99 \%$ con las especies Streptomyces novaecaesareae, Streptomyces cirratus y Streptomyces aureus respectivamente, las demás cepas presentaron similitud entre el 99\% y $98 \%$ con otras especies de Streptomyces aún sin identificar (Streptomyces spp.) (Tabla 3).

\section{Discusión}

En el presente estudio se logró el aislamiento de once cepas de actinobacterias rizosféricas de Stevia sp., silvestre. Todas las cepas fueron analizadas para algunos rasgos PGP en ensayos in vitro, y se encontró que ocho de ellas son capaces de crecer en un medio libre de nitrógeno y fijar el nitrógeno bajo la forma de amonio. Todas son capaces de solubilizar el fosfato y nueve fueron capaces de sintetizar ácido indol acético. La secuenciación de del gen ARNr 16S de estas

Tabla 3. Identificación de las cepas de actinobacterias aisladas por similitud genética por la secuencia del gen ARNr 16S.

\begin{tabular}{llcc}
\hline Aislados & \multicolumn{1}{c}{ Identificación } & Similitud & Accesión \\
\hline ST2A & Streptomyces sp. & $98 \%$ & MH700552 \\
ST2B & Streptomyces sp. & $99 \%$ & MH700553 \\
ST2E & Streptomyces sp. & $99 \%$ & MH700554 \\
ST3A & Streptomyces novaecaesareae & $99 \%$ & MH700555 \\
ST3E & Streptomyces cirratus & $99 \%$ & MH700556 \\
ST3F & Streptomyces sp. & $99 \%$ & MH700557 \\
ST5A & Streptomyces sp. & $99 \%$ & MH700558 \\
ST5B & Streptomyces sp. & $99 \%$ & MH700559 \\
ST5C & Streptomyces aureus & $99 \%$ & MH700560 \\
ST8A & Streptomyces sp. & $99 \%$ & MH700561 \\
ST8B & Streptomyces sp. & $99 \%$ & MH700562 \\
\hline
\end{tabular}


actinobacterias mostró similitud con las secuencias de los miembros del género Streptomyces.

En la literatura se reportan varias especies del género Streptomyces capaces de sintetizar AIA, metabolito que influye en el aumento del número y tamaño de las raíces (Himaman et al., 2016 y Sreevidya et al., 2016). En el presente trabajo la síntesis de AIA osciló entre $4.4 \mu \mathrm{g} / \mathrm{ml}$ y $19.1 \mu \mathrm{g} /$ ml., Streptomyces sp (ST2A), sintetizó $19.1 \mu \mathrm{g} / \mathrm{ml}$ de AIA, siendo esta la mejor cepa para la síntesis de esta fitohormona, quien superó a Streptomyces sp $(9.8 \mu \mathrm{g} / \mathrm{ml})$ reportado por Franco-Correa (2010) y Streptomyces sp $(12.4 \mu \mathrm{g} / \mathrm{ml})$ reportados por Sreevidya et al., (2016).

Los resultados del ensayo de inoculación permitieron identificar a Streptomyces sp (ST2A) como inductor del incremento del tamaño de la raíz de Allium sativum, resultados similares obtuvo Himaman et al. (2016) quienes reportan una cepa de Streptomices sp que promovió el incremento del tamaño de la raíz de las plántulas de eucalipto. El incremento del tamaño de la raíz conlleva a un incremento del área radicular lo que pude ser provechoso para las plantas, ya que aumenta el área de absorción de agua y nutrientes.

El fósforo es indispensable para el crecimiento vegetal, pero en la naturaleza se encuentra en su forma insoluble. Franco-Correa et al. (2010) reportan cepas de Streptomyces capaces de solubilizar el fosforo tricálcico, por medio de acidificación del medio y cepas solubilizadoras que no acidifican el medio de cultivo. En nuestro trabajo se detectó que todos los Streptomyces aislados fueron capaces de solubilizar el fósforo, y que uno de los mecanismos usados por los Streptomyces fue la acidificación del medio SARM. Estos resultados apoyan la necesidad de profundizar estos estudios cuantitativos para determinar el impacto en el rendimiento agrícola del ajo arequipeño.

La fijación del nitrógeno por rizobacterias diazótrofas está siendo muy estudiada, por la importancia de este elemento en la producción agrícola. Nuestros resultados revelan que los Streptomyces aislados de la rizósfera silvestre presentan la capacidad de crecer en un medio libre de nitrógeno, resultados que son corroborados por Yoshida et al. (2007), y Franco-Correa et al. (2010) quienes aislaron especies del género Streptomyces capaces de crecer en medio sin nitrógeno. Siguiendo la técnica del fenol hipoclorito de Lara et al. (2007) se detectó una concentración de $0,63 \mathrm{mg} / \mathrm{L}$ de amonio en el medio de cultivo de Streptomyces cirratus (ST3E). De acuerdo con Dahal et al. (2017) no se conocen Streptomyces fijadores de nitrógeno, es por ello que proponemos a Streptomyces cirratus (ST3E) como candidato para profundizar mayores estudios y confirmar la presencia de los genes nif y sus posibles mecanismos para poder fijar el nitrógeno atmosférico.

Los efectos como PGP de los Streptomyces rizosféricos silvestres aislados han generado un mejoramiento en los caracteres evaluados en el ajo (Figura 1). Los resultados del ensayo de inoculación con los Streptomyces han mostrado mejoramiento en el crecimiento del ajo en comparación con el tratamiento control (tierra estéril). Streptomyces cirratus (ST3E) aumentó significativamente $(\mathrm{P}<0,01)$ el tamaño del vástago y el peso seco, Streptomices sp (ST2A) aumentó significativamente $(\mathrm{p}<0,01)$ el tamaño de la raíz y las cepas de Streptomyces sp (ST8A) y Streptomyces sp (ST8B) aumentaron significativamente $(\mathrm{p}<0,01)$ el diámetro del bulbo del ajo. Estos resultados son corroborados por Goudjal et al. (2014), Sreevidya et al. (2016) y Anwar et al. (2016), quienes observaron aumento en el tamaño y peso seco de plántulas de tomate, garbanzo y trigo respectivamente, por efecto de inoculación con Streptomyces. El mejoramiento de las características evaluadas en las plántulas del ajo son efectos directos de las cepas aisladas de Streptomyces por ello estas cepas son buenos candidatos para ser incorporados en los bioformulados como agentes de biofertilización como promotores del crecimiento vegetal en los cultivos del ajo.

\section{Conclusión}

En este estudio se han identificado 11 cepas correspondientes del género Streptomyces, el análisis de las propiedades PGPR permitió identificar a 8 cepas capaces de fijar nitrógeno atmosférico, el cual se propone a Streptomyces cirratus (ST3E), como potencial candidato para profundizar estudios a nivel molecular como posible Streptomyces capaz de fijar el nitrógeno atmosférico. Este estudio revela que los Streptomyces cirratus (ST3E), Steptomyces sp (ST2A), Streptomyces sp (ST8A) y Streptomyces sp (ST8B), como buenos candidatos para ser incorporados en los bioformulados como agentes de biofertilización promotores del crecimiento vegetal en los cultivos del ajo. 


\section{Agradecimientos}

A la Universidad Nacional de San Agustín de Arequipa por el Financiamiento del proyecto
TT-0043-2016 al Laboratorio de Genética de la Facultad de Ciencias Biológicas por brindar las facilidades durante el desarrollo del proyecto.

\section{Literatura citada}

Anwar, S.; Basharat, A.; Sajid, I.

2016 Screening of Rhizospheric Actinomycetes for Various In vitro and In vivo Plant Growth Promoting (PGP) Traits and for Agroactive Compounds. Frontiers in microbiology, 7: 1334.

Kampfer P.

(2012) Genero 1. Streptomyces Waksman and Henrici 1943, 339AL. In: Goodfellow M, Kampfer P, Busse H-J, Trujillo M, Suzuki KE, Ludwig W, Whitman WB (eds) Bergey's manual of systematic bacteriology, vol. 5 Springer. New York, US. pp. 1455-1481.

Carro, L.; Persson, T.; Pujic, P.; Alloisio, N.; Fournier, P.;

Boubakri, H.; Pawlowski, K.; Normand, P.

2016. Organic acids metabolism in Frankia alni. Symbiosis, 1: $37-48$.

Dahal, B.; NandaKafle, G.; Perkins, L.; Volker, S.

2017. Diversity of free-Living nitrogen fixing Streptomyces in soils of the badlands of South Dakota. In Microbiological Research; 195: 31-39.

El-Tarabily, K.

2008. Promotion of tomato (Lycopersicon esculentum Mill.) plant growth by rhizosphere competent 1-aminocyclopropane1-carboxylic acid deaminase-producing streptomycete actinomycetes. Plant Soil. 308: 161-174.

Franco-Correa, M., Quintana, A.; Duque, C.; Suarez, C.; Rodríguez,

M.; Barea, J.

2010. Evaluation of actinomycete strains for key traits related with plant growth promotion and mycorrhiza helping activities. Applied Soil Ecology, 45: 209-217.

Ghanem, N.; Sabry, S.; El-sherif, Z.; Abu A.

2000. Isolation and Enumeration of marine Actinomycetes from seawater and sediments in Alexandria. The Journal of General and Applied and Microbiology, 46: 105-111.

Gordon, R.; Barnett, D.; Handerhan, J.; Pang, C.

1974. Nocardia coeliaca, Nocardia autotrophica, and the nocardin strain. International Journal of Systematic Bacteriology, 4: 54-63.

Goudjal, Y.; Toumatia, O.; Yekkour, A.; Sabaou, N.; Mathieu, F.; Zitouni, A.

2014. Biocontrol of Rhizoctonia solani damping-off and promotion of tomato plant growth by endophytic actinomycetes isolated from native plants of Algerian Sahara. Microbiological Research, 169: 59-65.

Himaman, W.; Thamchaipenet, A.; Pathom-aree, W.; Duangmal, K. 2016. Actinomycetes from Eucalyptus and their biological activities for controlling Eucalyptus leaf and shoot blight. Microbiological Research, 188: 42-52.

Huang, X., Zhang N.; Yong, X.; Yang, X.; Shen Q.

2011. Biocontrol of Rhizoctonia solani damping-off disease in cucumber with Bacillus pumilus SQR-N43. Microbiological Research, 167: 135-143.

Lara, C.; Villalba, M.; Oviedo, L.

2007. Bacterias fijadoras asimbióticas de nitrógeno en la zona agrícola de San Carlos de Colombia. Biotecnología. 10: 6-14.

Leiva, S.; Yáñez, M.; Zaror, L.; Rodríguez, H.; García, H.
2004. Actividad Antimicrobiana de actinomycetes aislados desde ambientes acuáticos del sur de Chile. Revista médica de Chile, 132: 151-159.

Minuto, A.; Spadaro, D.; Garibaldi, A.; Gullino, M.

2006. Control of soilborne pathogens of tomato using a commercial formulation of Streptomyces griseoviridis and solarization. Crop Protection, 25: 468-475.

Premono, M.; Moawad, A.; Vlek, P.

1996. Effect of phosphate-solubilizing Pseudomonas putida on the growth of maize and its survival in the rhizosphere. Indonesian Journal of Crop Science, 11: 13-23.

Seipke, R.; Barke, J.; Brearley, C.

2011. A single Streptomyces symbiont makes multiple antifungals to support the fungus farming ant Acromyrmex octospinosus. PLoS ONE, 6:e22028.

Sreevidya, M.; Gopalakrishnan, S.; Kudapa, H.; Varshney, R. 2016. Exploring plant growth-promotion actinomycetes from vermicompost and rhizosphere soil for yield enhancement in chickpea. Brazilian Journal of Microbiology, 47: 390-392.

Szkop, M.; Sikora, P.; Orzechowski, S.

2011. A novel, simple, and sensitive colorimetric method to determine aromatic amino acid aminotransferase activity using the Salkowski reagent. Folia Microbiologica, 57: 1-4.

Vázquez, P.; Holguin, G.; Puente, M.; López, A.; Bashan, Y.

2000. Phosphate solubilizing microorganisms associated with the rhizosphere of mangroves in a semiarid coastal lagoon. Biology and Fertility of Soils, 30: 400-408.

Williams, S., Goodfellow M.; Alderson, G.; Wellington, E.; Sneath, P.; Sackin, M.

1983. Numerical classification of Streptomyces and related genera. Journal of General Microbiology, 129: 1743-1813.

Xue, L.; Xue, Q.; Chen, Q.; Lin, C.; Shen, G.; Zhao, J.

2013. Isolation and evaluation of rhizosphere actinomycetes with potential application for biocontrol of Verticillium wilt of cotton. Crop Protection, 43: 231-240.

Yamanaka, T.; Okabe, H.; Kawai, S.

2016. Growth and nodulation in Alnus sieboldiana in response to Frankia inoculatio and nitrogen treatments. Trees, 30: 539-544.

Yin J.; Hoffmann, M.; Bian, X.; Tu, Q.; Yan, F.; Xia, L.; Ding, X.; Stewart, A.F.; Müller, R., Fu, J.; Zhang, Y.

2015. Direct cloning and heterologous expression of the salinomycin biosynthetic gene cluster from Streptomyces albus DSM41398 in Streptomyces coelicolor A3(2). Sci. Rep. 5: 15081.

Yoshida, N., Ohhata, N.; Yoshino, Y.; Katsuragi, T.; Tani, Y.; Takagi, $\mathrm{H}$.

2007. Screening of carbon dioxide-requiring extreme oligotrophs from soi. Bioscience Biotechnolgy and Biochemistry, 71: 2830-2832.

Zhang, J.; Liu, J.; Meng, L.; Ma, Z.; Tang, X.; Cao, Y.

2012. Isolation and characterization of plant growth-promoting rhizobacteria from wheat rhizosphere and their effect on plant growth promotion. Frontiers in Microbiology, 50: 191-198. 